\title{
EXISTENCE OF BEST PROXIMITY POINTS: GLOBAL OPTIMAL APPROXIMATE SOLUTION
}

\author{
HEMANT KUMAR NASHINE
}

\begin{abstract}
Given non-empty subsets $A$ and $B$ of a metric space, let $S: A \rightarrow B$ and $T: A \rightarrow B$ be non-self mappings. Taking into account the fact that, given any element $x$ in $A$, the distance between $x$ and $S x$, and the distance between $x$ and $T x$ are at least $d(A, B)$, a common best proximity point theorem affirms global minimum of both functions $x \rightarrow d(x, S x)$ and $x \rightarrow d(x, T x)$ by imposing a common approximate solution of the equations $S x=x$ and $T x=x$ to satisfy the constraint that $d(x, S x)=d(x, T x)=d(A, B)$. In this work we introduce a new notion of proximally dominating type mappings and derive a common best proximity point theorem for proximally commuting non-self mappings, thereby producing common optimal approximate solutions of certain simultaneous fixed point equations when there is no common solution. We furnish suitable examples to demonstrate the validity of the hypotheses of our results.
\end{abstract}

\section{INTRODUCTION}

Many problems of physical world are modelled in the form of operator equations. The fixed point equation $T x=x$ is one among them. Fixed point theory constitutes an important tool in dealing with such situations. A very powerful tool in solving existence problems in many branches of analysis is the Banach fixed point theorem [7] (or Banach's contraction principle), which assures that every contraction from a complete metric space into itself has a unique fixed point. Recall that a self-mapping $T: X \rightarrow X$, where $(X, d)$ is a metric space, is said to be a contraction if there exists $0<k<1$ such that for all $x, y \in X$,

$$
d(T x, T y) \leq k d(x, y) .
$$

2010 Mathematics Subject Classification. 41A65, 46B20, 47H10.

Key words and phrases. Optimal approximate solution, common best proximity point, common fixed point, proximally commuting mappings, proximally dominating mappings. 
In case, the fixed point equation does not possess a solution, the "Best approximation pair theorems" and "Best proximity pair theorems" are explored as alternative.

A best approximation theorem provides sufficient conditions to ascertain the existence of an element $x_{0}$, known as best approximant, such that

$$
d\left(x_{0}, T x_{0}\right)=d\left(T x_{0}, A\right)
$$

where $d(X, Y)=\inf \{p(x-y): x \in X$ and $y \in Y\}$ for any non-empty subsets $X$ and $Y$ of topological vector space $E$ with continuous seminorm $p$ and $T$ is mapping with domain $A$. An important contribution in this regards was made by Ky Fan [10] as below:

Theorem 1. [10]. Let $C$ be a non-empty compact convex subset of Hausdorff locally convex topological vector space $X$ with a continuous semi-norm $p$ and $T: C \rightarrow X$ is a single valued continuous map, then there exists an element $x_{0}$, called a best approximant, in $C$ such that

$$
p\left(x_{0}-T x_{0}\right)=d_{p}\left(T x_{0}, C\right)=\inf \left\{p\left(T x_{0}-y\right): y \in C\right\} .
$$

Subsequently, this result has been generalized in various directions by several authors, including Prolla [21], Reich [22] and Sehgal and Singh [31, 32]. Interestingly, Vetrivel et al. [34] have furnished the unification of all such best approximation theorems. Even though the best approximation theorems are congenial for providing an approximate solution to the equation $T x=x$, such results may fail to produce an approximate solution that is optimal. On the contrary, best proximity point theorems yield an approximate solution that is optimal. Indeed, a best proximity point theorem establishes sufficient conditions for the existence of an element $x$ such that the error $d(x, T x)$ is minimum. Essentially, a best proximity point theorem is devoted to the global minimization of the real valued function $x \rightarrow d(x, T x)$, which quantifies the error involved for an approximate solution of the equation $T x=x$. In light of the fact that, for a non-self mapping $T: A \rightarrow B$, $d(x, T x)$ is at least $d(A, B)$ for all $x$ in $A$ and $y$ in $B$, a best proximity point theorem accomplishes global minimum of the error $d(x, T x)$ by postulating an approximate solution $x$ of the equation $T x=x$ to satisfy the condition that $d(x, T x)=d(A, B)$. Such an optimal approximate solution of the equation $T x=x$ is designated as a best proximity point of the non-self mapping $T: A \rightarrow B$. Another interesting aspect of best proximity point theorems is that they evolve as a natural generalization of fixed point theorems, since a best proximity point becomes a fixed point if the underlying mapping is a self-mapping.

A best proximity point theorem for contraction has been elicited in [27]. Anuradha and Veeramani [6] have investigated best proximity point theorems for proximal pointwise contraction mappings. Also, best proximity 
point theorems for many variants of contractions can be found in $[1,4,9]$ and [14]. A best proximity point theorem for contractive mappings has been established in [26]. Anthony Eldred et al. [4] have examined a best proximity point theorem for relatively non-expansive mappings, a different approach to which has been considered in [30]. For detail see also [2]- [37] and their references therein.

Let us suppose that $A$ and $B$ are nonempty subsets of a metric space. Let $S: A \rightarrow B$ and $T: A \rightarrow B$ be non-self mappings. Considering the fact $S$ and $T$ are non-self-mappings, it is feasible that the equations $S x=x$ and $T x=x$ are likely to have no common solution, known as a common fixed point of the mappings $S$ and $T$. In fact, common best proximity point theorems scrutinize the existence of such optimal approximate solutions, known as common best proximity points, to the equations $S x$ and $T x$ in the event that the equations have no common solution. As a matter of fact, common best proximity point theorems inspect the existence of such optimal approximate solutions, called common best proximity points, to the equations $S x=x$ and $T x=x$ in the case that there is no common solution. It is highlighted that the real valued functions $x \rightarrow d(x, S x)$ and $x \rightarrow d(x, T x)$ assess the degree of the error involved for any common approximate solution of the equations $S x=x$ and $T x=x$. Considering the fact that, given any element $x$ in $A$, the distance between $x$ and $S x$, and the distance between $x$ and $T x$ are at least $d(A, B)$, a common best proximity point theorem affirms global minimum of both functions $x \rightarrow d(x, S x)$ and $x \rightarrow d(x, T x)$ by imposing a common approximate solution of the equations $S x=x$ and $T x=x$ to satisfy the constraint that $d(x, S x)=d(x, T x)=d(A, B)$.

The purpose of this paper is to furnish a solution to the problem that is more generic than the one just detailed. In this paper we introduce a generalized proximally dominating mappings for a pair of non-self maps and discuss the existence and uniqueness of a common best proximity point theorem presented in this paper assures a common optimal solution at which both the real-valued multiobjective functions $x \rightarrow d(x, T x)$ and $x \rightarrow d(x, S x)$ furnishing common optimal approximate solutions of simultaneous fixed point equations $S x=x$ and $T x=x$ in the circumstance that there is no exact common solution, where $S: A \rightarrow B$ and $T: A \rightarrow B$ are proximally commuting non-self mappings. We furnish suitable examples to demonstrate the validity of the hypotheses of our results. Our results are extension of the results of Basha [29]. Further, it subsumes a common fixed point theorem, due to Banach [7], Chatterjea [8], Hardy and Rogers [11], Jungck [12], Kannan [13] for commuting self-mappings. 


\section{Preliminaries}

Let $A$ and $B$ be two nonempty subsets of a metric space. This section recalls the following notation and notions that will be used in the subsequent section:

$$
\begin{gathered}
d(A, B):=\inf \{d(x, y): x \in A \text { and } y \in B\} \\
A_{0}:=\{x \in A: d(x, y)=d(A, B) \text { for some } y \in B\} \\
B_{0}:=\{y \in B: d(x, y)=d(A, B) \text { for some } x \in A\} .
\end{gathered}
$$

In the framework of normed linear spaces, if $A$ and $B$ are closed subsets satisfying the condition that $d(A, B)>0$, then it can be ascertained that $A_{0}$ and $B_{0}$ are contained in the boundaries of $A$ and $B$ respectively [24]. Furthermore, if $A$ intersects $B$, then $A \cap B$ is contained in both $A_{0}$ and $B_{0}$.

Definition 1. An element $x^{*}$ in $A$ is said to be a common best proximity point of the non-self mappings $S: A \rightarrow B$ and $T: A \rightarrow B$ if it satisfies the condition that $d\left(x^{*}, S x^{*}\right)=d\left(x^{*}, T x^{*}\right)=d(A, B)$.

It should be observed that a common best proximity point is an element at which the multi objective functions $x \rightarrow d(x, S x)$ and $x \rightarrow d(x, T x)$ attain common global minimum, since $d(x, S x) \geq d(A, B)$ and $d(x, T x) \geq d(A, B)$ for all $x$.

Definition 2. $A$ is said to be approximatively compact with respect to $B$ if every sequence $\left\{x_{n}\right\}$ of $A$ satisfying the condition that $d\left(y, x_{n}\right) \rightarrow d(y, A)$ for some $y$ in $B$ has a convergent subsequence.

It is evident that every set is approximatively compact with respect to itself. Also, every compact set is approximatively compact with respect to any set. Further, it can be seen that if $A$ is compact and $B$ is approximatively compact with respect to $A$, then the sets $A_{0}$ and $B_{0}$ are non-empty.

Definition 3. [29] The mappings $S: A \rightarrow B$ and $T: A \rightarrow B$ are said to commute proximally if they satisfy the condition that

$$
[d(u, S x)=d(v, T x)=d(A, B)] \Rightarrow S v=T u
$$

for all $x, u$ and $v$ in $A$.

It is easy to observe that proximal commutativity of self-mappings is just commutativity of the mappings.

Definition 4. [29] A mapping $T: A \rightarrow B$ is said to dominate a mapping $S: A \rightarrow B$ proximally if there exists a nonnegative number $\alpha<1$ such that

$$
d\left(u_{1}, S x_{1}\right)=d\left(u_{2}, S x_{2}\right)=d(A, B) \text { and } d\left(v_{1}, T x_{1}\right)=d\left(v_{2}, T x_{2}\right)=d(A, B)
$$

imply the inequality that

$$
d\left(u_{1}, u_{2}\right) \leq \alpha d\left(v_{1}, v_{2}\right)
$$


for all $u_{1}, u_{2}, v_{1}, v_{2}, x_{1}, x_{2}$ in $A$.

Next we introduce a generalized proximally dominating mappings for a pair of non-self maps.

Definition 5. A mapping $T: A \rightarrow B$ is said to dominate a mapping $S: A \rightarrow B$ generalized proximally of first kind if there exist non-negative numbers $\alpha, \beta$, $\gamma$ with $\alpha+2 \beta+2 \gamma<1$ such that

$$
d\left(u_{1}, S x_{1}\right)=d\left(u_{2}, S x_{2}\right)=d(A, B) \text { and } d\left(v_{1}, T x_{1}\right)=d\left(v_{2}, T x_{2}\right)=d(A, B)
$$

imply the inequality that

$$
d\left(u_{1}, u_{2}\right) \leq \alpha d\left(v_{1}, v_{2}\right)+\beta\left[d\left(v_{1}, u_{1}\right)+d\left(v_{2}, u_{2}\right)\right]+\gamma\left[d\left(v_{1}, u_{2}\right)+d\left(v_{2}, u_{1}\right)\right]
$$

for all $u_{1}, u_{2}, v_{1}, v_{2}, x_{1}, x_{2}$ in $A$.

If $\beta=0=\gamma$, then $T$ dominates $S$ proximally.

If $T$ and $S$ are self-mappings on $A$, then the requirement in the preceding definition reduces to the condition that

$$
\begin{aligned}
d\left(S x_{1}, S x_{2}\right) \leq \alpha d\left(T x_{1}, T x_{2}\right)+\beta\left[d \left(T x_{1},\right.\right. & \left.\left.S x_{1}\right)+d\left(T x_{2}, S x_{2}\right)\right] \\
& +\gamma\left[d\left(T x_{1}, S x_{2}\right)+d\left(T x_{2}, S x_{1}\right)\right] .
\end{aligned}
$$

The following example illustrates the notion of generalized proximally dominating mappings:

Example 1. Consider $R^{2}$ with Euclidean metric. Let

$$
A:=\{(x, y): x \leq 0\} \text { and } B:=\{(x, y): x \geq 1\} .
$$

Let $S: A \rightarrow B$ and $T: A \rightarrow B$ be defined as

$$
\begin{aligned}
& S(x, y)=\left(-3 x, \frac{y}{5}\right) \\
& T(x, y)=\left(-5 x, \frac{y}{3}\right) .
\end{aligned}
$$

Then, $d(A, B)=1, A_{0}=\{(0, y): y \in R\}$ and $B_{0}=\{(1, y): y \in R\}$. In addition, $T$ dominates $S$ generalized proximally of first kind for $\alpha=\frac{3}{5}$ and $\beta=\frac{1}{12}=\gamma$.

\section{COMmon Best PROXimity POINT FOR GENERALIZED PROXIMALly DOMINATING MAPPINGS}

In this section, we prove existence of a common best proximity point for generalized proximally dominating mappings and proximally commuting non-self mappings.

Theorem 2. Let $A$ and $B$ be non-empty closed subsets of a complete metric space. Also, assume that $A_{0}$ and $B_{0}$ are non-empty. Let the non-self mappings $S: A \rightarrow B$ and $T: A \rightarrow B$ satisfy the following conditions: 
(a) $T$ dominates $S$ generalized proximally of first kind;

(b) $S$ and $T$ are continuous;

(c) $S$ and $T$ commute proximally;

(d) $S\left(A_{0}\right) \subseteq B_{0}$;

(e) $S\left(A_{0}\right) \subseteq T\left(A_{0}\right)$.

Then, there exists an unique element $x \in A$ such that

$$
d(x, T x)=d(A, B), d(x, S x)=d(A, B) .
$$

Proof. Let $x_{0}$ be an element in $A_{0}$. The fact that $S\left(A_{0}\right)$ is contained in $T\left(A_{0}\right)$ guarantees the existence of an element $x_{1}$ in $A_{0}$ such that $S x_{0}=T x_{1}$. Again, since $S\left(A_{0}\right)$ is contained in $T\left(A_{0}\right)$, there exists an element $x_{2}$ in $A_{0}$ satisfying the condition that $S x_{1}=T x_{2}$. This process can be continued. Proceeding inductively, it is easy to assert that there exists a sequence $\left\{x_{n}\right\}$ of elements in $A_{0}$ such that

$$
S x_{n-1}=T x_{n}
$$

for all positive integral values of $n$, because of the fact $S\left(A_{0}\right)$ is contained in $T\left(A_{0}\right)$.

On account of the fact that $S\left(A_{0}\right)$ is contained in $B_{0}$, there exists an element $u_{n}$ in $A_{0}$ such that

$$
d\left(S x_{n}, u_{n}\right)=d(A, B)
$$

for all positive integral values of $n$.

Further, it follows from the choice of $x_{n}$ and $u_{n}$ that

$$
\begin{aligned}
d\left(S x_{n+1}, u_{n+1}\right) & =d(A, B), \\
d\left(T x_{n}, u_{n-1}\right) & =d(A, B), \\
d\left(T x_{n+1}, u_{n-1}\right) & =d(A, B) .
\end{aligned}
$$

By the generalized proximally dominating property, we have

$$
\begin{gathered}
d\left(u_{n}, u_{n+1}\right) \leq \alpha d\left(u_{n-1}, u_{n}\right)+\beta\left[d\left(u_{n-1}, u_{n}\right)+d\left(u_{n}, u_{n+1}\right)\right] \\
\quad+\gamma d\left(u_{n-1}, u_{n+1}\right) \\
\leq \alpha d\left(u_{n-1}, u_{n}\right)+\beta\left[d\left(u_{n-1}, u_{n}\right)+d\left(u_{n}, u_{n+1}\right)\right] \\
\quad+\gamma\left[d\left(u_{n-1}, u_{n}\right)+d\left(u_{n}, u_{n+1}\right)\right] .
\end{gathered}
$$

This implies that

$$
d\left(u_{n}, u_{n+1}\right) \leq k d\left(u_{n-1}, u_{n}\right)
$$

where the constant $k=\frac{\alpha+\beta+\gamma}{1-\beta-\gamma}$ is strictly less than 1 . It follows that $\left\{u_{n}\right\}$ is a Cauchy sequence and hence converges to some $u$ in $A$. Because of the fact that the mappings $S$ and $T$ are commuting proximally,

$$
T u_{n}=S u_{n-1}
$$


for every positive integer $n$.

Therefore, the continuity of the mappings $S$ and $T$ ensures that $S u$ and $T u$ are identical.

In view of the fact that $S\left(A_{0}\right)$ is contained in $B_{0}$, there exists an element $x$ in $A$ such that

$$
d(x, S u)=d(A, B), d(x, T u)=d(A, B) .
$$

As $S$ and $T$ commute proximally, $S x$ and $T x$ are identical.

Then since $S\left(A_{0}\right)$ is contained in $B_{0}$, there exists an element $z$ in $A$ such that

$$
d(z, S x)=d(A, B), d(z, T x)=d(A, B) .
$$

From (3), we have

$$
d(x, z) \leq(\alpha+2 \gamma) d(x, z),
$$

which implies that $x=z$, that is, $x$ and $z$ are identical.

Thus, it follows that

$$
\begin{aligned}
& d(x, T x)=d(z, T x)=d(A, B), \\
& d(x, S x)=d(z, S x)=d(A, B) .
\end{aligned}
$$

Therefore, $x$ is a common best proximity point of the nonself-mappings $S$ and $T$.

Suppose that $x^{*}$ is another common best proximity point of the mappings $S$ and $T$ so that

$$
\begin{aligned}
d\left(x^{*}, S x^{*}\right) & =d(A, B) \\
d\left(x^{*}, T x^{*}\right) & =d(A, B) .
\end{aligned}
$$

From (3), we have

$$
d\left(x, x^{*}\right) \leq(\alpha+2 \gamma) d\left(x, x^{*}\right),
$$

which in turn implies that $x=x^{*}$. This completes the proof of the theorem.

The following example demonstrates the validity of the Theorem 2 :

Example 2. Consider $R^{2}$ with Euclidean metric. Let

$$
A:=\{(x, y): x \leq 0\} \text { and } B:=\{(x, y): x \geq 1\} .
$$

Let $S: A \rightarrow B$ and $T: A \rightarrow B$ be defined as

$$
\begin{aligned}
& S(x, y)=\left(-4 x, \frac{y}{5}\right) \\
& T(x, y)=\left(-5 x, \frac{y}{4}\right) .
\end{aligned}
$$

Then, $d(A, B)=1, A_{0}=\{(0, y): y \in R\}$ and $B_{0}=\{(1, y): y \in R\}$. Moreover, $T$ dominate $S$ generalized proximally of first kind for $\alpha=\frac{4}{5}$ and 
$\beta=\frac{1}{30}=\gamma$ with $\alpha+2 \beta+2 \gamma<1$. It is easy to see that the other hypotheses of Theorem 2 are satisfied. Furthermore, $(0,0)$ is a unique common best proximity point of $S$ and $T$.

\section{Consequences}

In this section, we derive some fixed point theorems from our main result given by Theorem 2 .

Corollary 1. Let $A$ and $B$ be non-empty closed subsets of a complete metric space. Also, assume that $A_{0}$ and $B_{0}$ are non-empty. Let the non-self mappings $S: A \rightarrow B$ and $T: A \rightarrow B$ satisfy the following conditions:

(a)' $T$ dominates $S$ proximally such that

$$
d\left(u_{1}, u_{2}\right) \leq \alpha d\left(v_{1}, v_{2}\right)+\beta\left[d\left(v_{1}, u_{1}\right)+d\left(v_{2}, u_{2}\right)\right]
$$

for all $u_{1}, u_{2}, v_{1}, v_{2}, x_{1}, x_{2}$ in $A$, where $\alpha, \beta$ are non-negative numbers with $\alpha+2 \beta<1$;

(b)' $S$ and $T$ are continuous;

(c)' $S$ and $T$ commute proximally;

(d)' $S\left(A_{0}\right) \subseteq B_{0}$;

(e)' $S\left(A_{0}\right) \subseteq T\left(A_{0}\right)$.

Then, there exists an unique element $x \in A$ such that

$$
d(x, T x)=d(A, B), d(x, S x)=d(A, B) .
$$

Corollary 2. Let $A$ and $B$ be non-empty closed subsets of a complete metric space. Also, assume that $A_{0}$ and $B_{0}$ are non-empty. Let the non-self mappings $S: A \rightarrow B$ and $T: A \rightarrow B$ satisfy the following conditions:

(a)" $T$ dominates $S$ proximally such that

$$
d\left(u_{1}, u_{2}\right) \leq \alpha d\left(v_{1}, v_{2}\right)+\gamma\left[d\left(v_{1}, u_{2}\right)+d\left(v_{2}, u_{1}\right)\right]
$$

for all $u_{1}, u_{2}, v_{1}, v_{2}, x_{1}, x_{2}$ in $A$, where $\alpha, \gamma$ are non-negative numbers with $\alpha+2 \gamma<1$;

(b)" $S$ and $T$ are continuous;

(c)" $S$ and $T$ commute proximally;

(d)" $S\left(A_{0}\right) \subseteq B_{0}$;

(e)" $S\left(A_{0}\right) \subseteq T\left(A_{0}\right)$.

Then, there exists an unique element $x \in A$ such that

$$
d(x, T x)=d(A, B), d(x, S x)=d(A, B) .
$$

Remark 1. Corollary 1 and 2 extend and generalizes the Theorem 3.1 [29].

Corollary 3. Let $X$ be a complete metric space. Let the self mappings $S: X \rightarrow X$ and $T: X \rightarrow X$ satisfy the following conditions: 
(a)" there are non-negative real numbers $\alpha, \beta$ with $\alpha+2 \beta<1$ such that

$$
\begin{aligned}
& d\left(S x_{1}, S x_{2}\right) \leq \alpha d\left(T x_{1}, T x_{2}\right)+\beta\left[d\left(T x_{1}, S x_{1}\right)+d\left(T x_{2}, S x_{2}\right)\right] \\
&+\gamma\left[d\left(T x_{1}, S x_{2}\right)+d\left(T x_{2}, S x_{1}\right)\right]
\end{aligned}
$$

for all $x_{1}$ and $x_{2}$ in $X$;

(b)", $T$ is continuous;

(c)" $S$ and $T$ commute;

(d)" ' $S(X) \subseteq T(X)$.

Then, the mappings $S$ and $T$ have a unique common fixed point.

Remark 2. Corollary 3 extends and generalizes many existing fixed point theorems in the literature $[7,8,11,12,13]$.

\section{REFERENCES}

[1] M. A. Al-Thagafi and N. Shahzad, Convergence and existence results for best proximity points, Nonlinear Anal., 70 (10) (2009), 3665-3671, doi:10.1016/j.na.2008.07.022.

[2] M.A. Al-Thagafi and N. Shahzad, Best proximity pairs and equilibrium pairs for Kakutani multimaps, Nonlinear Anal., 70 (3), (2009), 1209-1216, doi:10.1016/ j.na.2008.02.004.

[3] M. A. Al-Thagafi and N. Shahzad, Best proximity sets and equilibrium pairs for a finite family of multimaps, Fixed Point Theory Appl., (2008), page 10, (Article ID 457069).

[4] A. Anthony Eldred and P. L. Veeramani, Existence and convergence of best proximity points, J. Math. Anal. Appl., 323 (2006), 1001-1006, doi:10.1016/j.jmaa.2005.10.081.

[5] A. Anthony Eldred, V. A. Kirk and P. Veeramani, Proximinal normal structure and relatively nonexpanisve mappings, Studia Math., 171 (3) (2005), 283-293, doi:10.4064/sm171-3-5.

[6] J. Anuradha and P. Veeramani, Proximal pointwise contraction, Topol. Appl., 156 (18)(2009), 2942-2948, doi:10.1016/j. topol.2009.01.017.

[7] S. Banach, Sur les opérations dans les ensembles abstraits et leur application aux equations itegrales, Fund. Math., 3 (1922), 133-181.

[8] S. K. Chatterjea, Fixed point theorems, C.R. Acad. Bulgare Sci., 25 (1972), 727-730.

[9] C. Di Bari, T. Suzuki and C. Vetro, Best proximity points for cyclic Meir-Keeler contractions, Nonlinear Anal., 69 (11) (2008), 3790-3794, doi:10.1016/j.na.2007.10.014.

[10] K. Fan, Extensions of two fixed point theorems of F. E. Browder, Math. Z., 112 (1969), 234-240, doi:10.1007/BF01110225.

[11] G. E. Hardy and T. D. Rogers, A Generalization of a fixed point theorem of Reich, Canad. Math. Bull., 16 (2) (1973), 201-206.

[12] G. Jungck, Commuting mappings and fixed points, Am. Math. Mon., 83 (1976), 261263.

[13] R. Kannan, Some results on fixed points, Bull. Calcutta Math. Soc., 10 (1968), 71-76.

[14] S. Karpagam and S. Agrawal, Best proximity point theorems for p-cyclic Meir-Keeler contractions, Fixed Point Theory Appl., 9 (2009), Article ID 197308.

[15] W. K. Kim, S. Kum and K. H. Lee, On general best proximity pairs and equilibrium pairs in free abstract economies, Nonlinear Anal., 68 (8) (2008), 2216-2227, doi:10.1016/j.na.2007.01.057. 
[16] W. A. Kirk, S. Reich and P. Veeramani, Proximinal retracts and best proximity pair theorems, Numer. Funct. Anal. Optim., 24 (2003), 851-862, doi:10.1081/NFA120026380.

[17] H. K. Nashine and C. L. Dewangan, An application of KKM-map principle to best proximity pair, Varahmihir J. Math. Sci., 6 (1) (2006), 49-55.

[18] H. K. Nashine and C. L. Dewangan, Existence results on best proximity pair for multifunction, Afr. Diaspora J. Math., 5 (1) (2007), 71-81.

[19] H. K. Nashine, Existence results on best proximity pair in metrizable topological vector spaces, Nonlinear Funct. Anal. Appl., 13 (4) (2008), 587-596.

[20] H. K. Nashine, C. L. Dewangan and Z. D. Mitrović, Best proximity pair theorem in metrizable topological vector spaces, Anal. Theory Appl., 26 (1) (2010), 59-68.

[21] J. B. Prolla, Fixed point theorems for set valued mappings and existence of best approximations, Numer. Funct. Anal. Optim., 5 (1982), 449-455.

[22] S. Reich, Approximate selections, best approximations, fixed points and invariant sets, J. Math. Anal. Appl., 62 (1978), 104-113, doi:10.1016/0022-247X(78)90222-6.

[23] S. Sadiq Basha and P. Veeramani, Best approximations and best proximity pairs, Acta Sci. Math. (Szeged), 63 (1997), 289-300.

[24] S. Sadiq Basha and P. Veeramani, Best proximity pair theorems for multifunctions with open fibres, J. Approx. Theory, 103 (2000), 119-129, doi:10.1006/jath.1999.3415.

[25] S. Sadiq Basha, P. Veeramani and D. V. Pai, Best proximity pair theorems, Indian J. Pure Appl. Math., 32 (2001), 1237-1246.

[26] S. Sadiq Basha, Best proximity points: global optimal approximate solution, J. Glob. Optim., (2010), doi:10.1007/s10898-009-9521-0.

[27] S. Sadiq Basha, Extensions of Banach's contraction principle, Numer. Funct. Anal. Optim., 31 (2010), 569-576, doi:10.1080/ 01630563.2010.485713.

[28] S. Sadiq Basha, Common best proximity points: global minimization of multi-objective functions, J. Glob. Optim., DOI 10.1007/s10898-011-9760-8.

[29] S. Sadiq Basha, Common best proximity points: global minimal solutions, J. Glob. Optim., DOI 10.1007/s11750-011-0171-2.

[30] V. Sankar Raj and P. Veeramani, Best proximity pair theorems for relatively nonexpansive mappings, Appl. Gen. Topol., 10 (1) (2009), 21-28.

[31] V. M. Sehgal and S. P. Singh, A generalization to multifunctions of Fan's best approximation theorem, Proc. Am. Math. Soc., 102 (1988), 534-537.

[32] V. M. Sehgal and S. P. Singh, A theorem on best approximations, Numer. Funct. Anal. Optim., 10 (1989), 181-184, doi:10.1080/01630568908816298.

[33] P. S. Srinivasan, Best proximity pair theorems, Acta Sci. Math. (Szeged), 67 (2001), 421-429.

[34] V. Vetrivel, P. Veeramani and P. Bhattacharyya, Some extensions of Fan's best approximation theorem, Numer. Funct. Anal. Optim., 13 (1992), 397-402, doi:10.1080/ 01630569208816486.

[35] K. Wlodarczyk, R. Plebaniak and A. Banach, Best proximity points for cyclic and noncyclic set-valued relatively quasiasymptotic contractions in uniform spaces, Nonlinear Anal., 70 (9) (2009), 3332-3341, doi:10.1016/j.na.2008.04.037.

[36] K. Wlodarczyk, R. Plebaniak and A. Banach, Erratum to: best proximity points for cyclic and noncyclic set-valued relatively quasi-asymptotic contractions in uniform spaces, Nonlinear Anal., 71 (2009), 3585-3586, [Nonlinear Anal., 70 (2009), 33323341 ], doi:10.1016/j.na.2008.11.020. 
[37] K. Wlodarczyk, R. Plebaniak and C. Obczynski, Convergence theorems, best approximation and best proximity for set-valued dynamic systems of relatively quasiasymptotic contractions in cone uniform spaces, Nonlinear Anal. 72 (2010), 794-805. doi:10.1016/j.na.2009.07.024.

(Received: January 6, 2013)

\author{
Department of Mathematics \\ Disha Institute of Management and Technology \\ Satya Vihar, Vidhansabha-Chandrakhuri Marg \\ Mandir Hasaud \\ Raipur-492101 (Chhattisgarh) \\ India \\ drhknashine@gmail.com
}

